\title{
The impact of the aortic cusps fusion pattern and valve disease severity on the aortic wall mechanics in patients with bicuspid aortic valve
}

\author{
Mariusz E. Kalinowski ${ }^{1} \cdot$ Mariola Szulik ${ }^{2}$ Szymon Pawlak ${ }^{3} \cdot$ Barbara Rybus-Kalinowska $^{4} \cdot$ Marian Zembala $^{1}$. \\ Zbigniew Kalarus $^{2} \cdot$ Tomasz Kukulski $^{2}$
}

Received: 15 November 2019 / Accepted: 2 April 2020 / Published online: 17 April 2020

(c) The Author(s) 2020

\begin{abstract}
The ascending aorta dilatation in the bicuspid aortic valve (BAV) patients is often attributed to congenital abnormalities of the aortic wall, but it may be related to hemodynamic disturbances in the course of BAV disease. At present, ascending aortic diameter is used as almost sole but weak predictor of aortic dissection and rupture in BAV. We examined the association between aortic wall mechanics and severity of aortic valve disease including different cusps fusion patterns using conventional echocardiography and tissue Doppler imaging (TDI). We prospectively studied 106 BAV patients: 72 with right-left (R-L) coronary cusp fusion were matched 1:1 to 34 patients with right-noncoronary (R-N) cusp fusion obtaining 34 pairs of patients. Peak systolic radial velocity and acceleration of the ascending aortic wall, measured by TDI, were used as an index of hemodynamic stress imposed on the aorta. Paired analysis showed higher aortic wall radial velocity $(4.71 \pm 1.61 \mathrm{~cm} / \mathrm{s}$ vs. $3.33 \pm 1.44 \mathrm{~cm} / \mathrm{s}, \mathrm{p}=0.001)$ and acceleration $\left(1.08 \pm 0.46 \mathrm{~m} / \mathrm{s}^{2}\right.$ vs. $\left.0.80 \pm 0.34 \mathrm{~m} / \mathrm{s}^{2}, \mathrm{p}=0.015\right)$ in-R-L compared to R-N fusion. Pearson correlation showed association of ascending tubular aortic diameter with age $(r=0.258, p=0.012)$, weight $(\mathrm{r}=0.323, \mathrm{p}=0.001)$, peak aortic valve gradient $(\mathrm{r}=0.386, \mathrm{p}=0.0001)$, aortic root diameter $(\mathrm{r}=0.439, \mathrm{p}<0.0001)$, and $\mathrm{R}-\mathrm{N}$ fusion pattern $(r=0.209, p=0.043)$. Aortic root diameter was related to male gender $(r=0.296, p=0.003)$, weight $(r=0.381$, $\mathrm{p}=0.0001)$, ascending aortic diameter $(\mathrm{r}=0.439, \mathrm{p}<0.0001)$, and severity of aortic regurgitation $(\mathrm{r}=0.337, \mathrm{p}=0.0009)$. Regional differences in aortic wall motion between different BAV cusp fusion patterns and association of aortic diameters with the severity of aortic valve disease, both suggest a deleterious hemodynamic impact of cusp fusion patterns and aortic valve dysfunction on ascending aortic wall. Assessment of aortic hemodynamic by TDI is feasible and could be potentially used to improve prediction of acute aortic complications, thus helping to establish optimal timing of aortic surgery in BAV patients.
\end{abstract}

Keywords Bicuspid aortic valve $\cdot$ Cusp fusion $\cdot$ Aortopathy $\cdot$ Hemodynamic $\cdot$ Mechanics $\cdot$ Tissue doppler imaging

\section{Abbreviations}

BAV Bicuspid aortic valve

TDI Tissue Doppler imaging

Tomasz Kukulski

tomasz.kukulski@sccs.pl

1 Department of Cardiac, Vascular and Endovascular Surgery and Transplantation, Silesian Center for Heart Diseases, Faculty of Medical Science in Zabrze, Medical University of Silesia, Katowice, Poland

2 Department of Cardiology, Congenital Heart Diseases and Electrotherapy, Silesian Center for Heart Diseases, Faculty of Medical Science in Zabrze, Medical University of Silesia, Katowice, Poland
3 Department of Cardiac Surgery, Heart Transplantation and Mechanical Support in Children, Silesian Center for Heart Diseases, Zabrze, Faculty of Medical Science in Zabrze, Medical University of Silesia, Katowice, Poland

4 Department of Basic Medical Sciences, School of Public Health in Bytom, Medical University of Silesia, Katowice, Poland 


\section{Introduction}

Bicuspid aortic valve (BAV) is the commonest congenital heart defect in adults, occurring in $1-2 \%$ of the population, more frequently in men [1]. BAV is associated with an increased incidence of aortic stenosis and regurgitation, coarctation of the aorta, and ascending aortic dilatation, which may lead to aortic dissection and rupture [2, 3]. Familial clustering of BAV is observed, consistent with autosomal dominant mode of inheritance with incomplete penetration [4].

Ascending aortic dilatation and aneurysm formation is a characteristic feature of BAV. The pathogenesis of aortopathy in BAV is not fully understood [5]. Early echocardiographic studies have reported that ascending aortic dilatation is out of proportion to the severity of aortic valve disease, suggesting intrinsic abnormalities of the aortic wall $[6,7]$. The results of a subsequent, larger echocardiographic and magnetic resonance imaging (MRI) flow sensitive studies on BAV, suggest that disturbed flow generated by abnormal aortic valve imposes an increased hemodynamic load on the ascending aortic wall leading to the progressive aortic dilatation $[8,9]$.

A preliminary study demonstrated feasibility of tissue Doppler imaging (TDI) in the assessment of aortic hemodynamic. Increased hemodynamic stress imposed on the ascending aortic wall has been shown in bicuspid aortic valve disease but not in tricuspid stenotic aortic valve [10]. We hypothesized that BAV fusion pattern is associated with hemodynamic stress imposed on the ascending aorta, which can be assessed by TDI. The relationship between severity of aortic valve disease and dilatation of the ascending aorta was also studied.

One of the main problems of BAV is poor prediction of ascending aorta complications like aortic dissection and rupture. So far, mainly ascending aortic diameter was used to anticipate such complications, but with a poor predictive value, thus more parameters are needed for better aortic surveillance in BAV.

\section{Materials and methods}

\section{Subjects}

The study group consisted of $106 \mathrm{BAV}$ patients seen at our institution (mean age, $46 \pm 16$ years; 15 women). Echocardiographic examinations, including TDI acquisition were performed prospectively in all patients between December 2006 and February 2015.

Exclusion criteria were; moderate to severe valvular and congenital heart disease other than BAV, aortic dissection or coarctation, previous myocardial infarction or cardiac surgery, Marfan's syndrome, atrial fibrillation, and permanent RV pacing. BAV cusp fusion patterns were determined by two-dimensional echocardiography.

Seventy two patients with right and left coronary cusp fusion were matched 1:1 to 34 patients with right and noncoronary cusps fusion for age, gender, the severity of aortic stenosis and regurgitation, the diameter of aortic root and mid-ascending aorta, and systolic blood pressure

Table 1 Clinical and echocardiographic parameters in bicuspid aortic valve patients with right-left coronary and right-noncoronary cusp fusion

\begin{tabular}{|c|c|c|c|c|}
\hline Variables $(n=106)$ & All patients $(\mathrm{n}=106)$ & $\begin{array}{l}\text { Right-left coronary cusp } \\
\text { fusion }(\mathrm{n}=72)\end{array}$ & $\begin{array}{l}\text { Right-noncoronary cusp } \\
\text { fusion }(\mathrm{n}=34)\end{array}$ & $P$ value \\
\hline Age (years) & $45.4 \pm 15.9$ & $44.2 \pm 15.4$ & $48.2 \pm 16.7$ & 0.253 \\
\hline Gender: male, n (\%) & $91(85 \%)$ & $61(84 \%)$ & $30(88 \%)$ & 0.852 \\
\hline Height $(\mathrm{cm})$ & $173.1 \pm 8.43$ & $173.2 \pm 8.92$ & $173.1 \pm 7.30$ & 0.924 \\
\hline Weight (kg) & $80.5 \pm 10.8$ & $80.1 \pm 10.8$ & $81.8 \pm 10.9$ & 0.507 \\
\hline Systolic blond pressure (mmHg) & $129.4 \pm 20.6$ & $131.7 \pm 20.4$ & $126.3 \pm 20.8$ & 0.242 \\
\hline Diastolic blond pressure $(\mathrm{mmHg})$ & $76.7 \pm 14.1$ & $77.2 \pm 14.9$ & $75.7 \pm 12.5$ & 0.681 \\
\hline Aortic Root diameter (mm) & $40.1 \pm 7.21$ & $40.3 \pm 6.97$ & $39.5 \pm 7.61$ & 0.574 \\
\hline Ascending aortic diameter $(\mathrm{mm})$ & $41.7 \pm 6.44$ & $40.8 \pm 6.04$ & $43.5 \pm 6.77$ & 0.046 \\
\hline AV peak gradient $(\mathrm{mmHg})$ & $17.3 \pm 13.1$ & $15.7 \pm 11.5$ & $21.0 \pm 15.03$ & 0.035 \\
\hline AV mean gradient $(\mathrm{mmHg})$ & $9.55 \pm 7.85$ & $8.52 \pm 6.83$ & $11.3 \pm 9.28$ & 0.048 \\
\hline Aortic regurgitation: $\geq$ moderate & $61(57 \%)$ & $40(55 \%)$ & $21(61 \%)$ & 0.694 \\
\hline $\operatorname{LVEF}(\%)$ & $54.2 \pm 5.34$ & $54.3 \pm 4.9$ & $54.0 \pm 5.8$ & 0.983 \\
\hline Velocity of aortic wall by TDI $(\mathrm{cm} / \mathrm{s})$ & $4.04 \pm 1.60$ & $4.43 \pm 1.66$ & $3.33 \pm 1.44$ & 0.005 \\
\hline Acceleration of aortic wall by TDI $\left(\mathrm{m} / \mathrm{s}^{2}\right)$ & $0.96 \pm 0.45$ & $1.04 \pm 0.48$ & $0.80 \pm 0.34$ & 0.010 \\
\hline
\end{tabular}

Bold numbers indicate significance at $\mathrm{P}<0.05$

$A V$ aortic valve, $L V E F$ left ventricular ejection fraction, $T D I$ tissue Doppler imaging, $\geq$ moderate: moderate to severe 
(Table 1). As a result, 34 matched pairs of patients were obtained. After matching, groups of patients with different patterns of BAV cusp fusion were comparable $(\mathrm{p}=\mathrm{NS})$ with respect to the above-mentioned and remaining variables (Table 2).

\section{Echocardiography}

Echocardiographic examinations were performed with a commercially available system (Vivid 5, Horten, Norway and Vivid E9, GE Healthcare) equipped with a 2.5- and 3.5 MHz transducers, respectively, by the single experienced echocardiographer (M.E.K), in patients lying on supine using both left and right lateral position.

Left ventricular EF was calculated using the biplane modified Simpson's rule. The inner diameter of the aortic root and ascending aorta was measured at end-diastole on two-dimensional echocardiography. Ascending aortic diameter was measured distal to the sinotubular junction, at the point of maximal aortic dilatation. Images were obtained in the parasternal long-axis view, perpendicular to the long axis of the aorta.

The aortic valve was observed in multiple views, but the diagnosis of BAV and determination of the cusp fusion pattern was based on the parasternal short-axis view showing only two aortic cusps in systole and diastole. The severity of aortic stenosis and aortic regurgitation was determined by standard methods as recommended by the EACVI/ASE [11].

\section{Quantification of the aortic wall function}

A color doppler tissue imaging data of the mid-ascending anterior aortic wall were collected in the parasternal longaxis view, perpendicular to the long axis of the aorta, at a high frame rate (mean: 177 frames/s) and the aliasing velocity of $16 \mathrm{~cm} / \mathrm{s}$. A color tissue doppler images were stored digitally and subsequently transferred to a workstation (EchoPac 6.4.2, GEVingmed Ultrasound 2003) for subsequent off-line analysis.

A $3 \times 3$ pixel region of interest was placed over the anterior wall of the mid-ascending aorta, $3 \mathrm{~cm}$ above the aortic valve. Manual tracking of the sample volume was performed on a frame-by-frame basis throughout the cardiac cycle. Velocity curves were constructed and peak systolic velocity and acceleration were measured and averaged from three consecutive cardiac cycles (Fig. 1).

\section{Statistical analysis}

Continuous variables are presented as a mean \pm SD and categorical variables as the numbers and percentages. An optimal matching for propensity score was used to match BAV patients with right-left coronary cusp fusion to patients with right-non coronary fusion. Comparisons between the matched groups of patients were made with Mann-Whitney $U$ test. Pearson correlation coefficients were used to evaluate correlations between aortic diameters and other parameters.

The distributions of transvalvular aortic gradients were skewed and therefore log-transformed for correlation
Table 2 Clinical and echocardiographic parameters in matched groups of patients with bicuspid aortic valve

\begin{tabular}{llll}
\hline Variables $(\mathrm{n}=106)$ & $\begin{array}{l}\text { Right-left coronary } \\
\text { cusp fusion }(\mathrm{n}=34)\end{array}$ & $\begin{array}{l}\text { Right-noncoronary } \\
\text { cusp fusion }(\mathrm{n}=34)\end{array}$ & P value \\
\hline Age (years) & $45.2 \pm 15.0$ & $48.2 \pm 16.7$ & 0.523 \\
Gender: male, $\mathrm{n}(\%)$ & $30(88 \%)$ & $30(88 \%)$ & 1.000 \\
Height $(\mathrm{cm})$ & $173.2 \pm 8.28$ & $173.1 \pm 7.30$ & 0.707 \\
Weight $(\mathrm{kg})$ & $80.1 \pm 10.3$ & $81.8 \pm 10.9$ & 0.610 \\
Systolic blond pressure $(\mathrm{mmHg})$ & $128.9 \pm 16.0$ & $126.3 \pm 20.8$ & 0.606 \\
Diastolic blond pressure $(\mathrm{mmHg})$ & $76.9 \pm 13.5$ & $75.7 \pm 12.5$ & 0.955 \\
Aortic Root diameter $(\mathrm{mm})$ & $39.5 \pm 7.20$ & $39.5 \pm 7.61$ & 0.820 \\
Ascending aortic diameter $(\mathrm{mm})$ & $42.3 \pm 6.23$ & $43.5 \pm 6.77$ & 0.410 \\
AV peak gradient $(\mathrm{mmHg})$ & $19.5 \pm 14.2$ & $21.0 \pm 15.0$ & 0.749 \\
AV mean gradient $(\mathrm{mmHg})$ & $10.6 \pm 8.74$ & $11.3 \pm 9.28$ & 0.712 \\
Aortic regurgitation: $\geq$ moderate & $20(58 \%)$ & $21(61 \%)$ & 1.000 \\
LVEF $(\%)$ & $54.1 \pm 5.0$ & $54.0 \pm 5.8$ & 0.995 \\
Velocity of aortic wall by TDI $(\mathrm{cm} / \mathrm{s})$ & $4.71 \pm 1.61$ & $3.33 \pm 1.44$ & $\mathbf{0 . 0 0 1}$ \\
Acceleration of aortic wall by TDI $\left(\mathrm{m} / \mathrm{s}^{2}\right)$ & $1.08 \pm 0.46$ & $0.80 \pm 0.34$ & $\mathbf{0 . 0 1 5}$ \\
\hline
\end{tabular}

Bold numbers indicate significance at $\mathrm{P}<0.05$

The patients with different cusp fusion pattern were matched for age, gender, aortic root and ascending aortic diameter, peak aortic valve gradient, severity of aortic regurgitation, and systolic blood pressure

$A V$ aortic valve, $L V E F$ left ventricular ejection fraction, TDI tissue doppler imaging, $\geq$ moderate: moderate to severe 


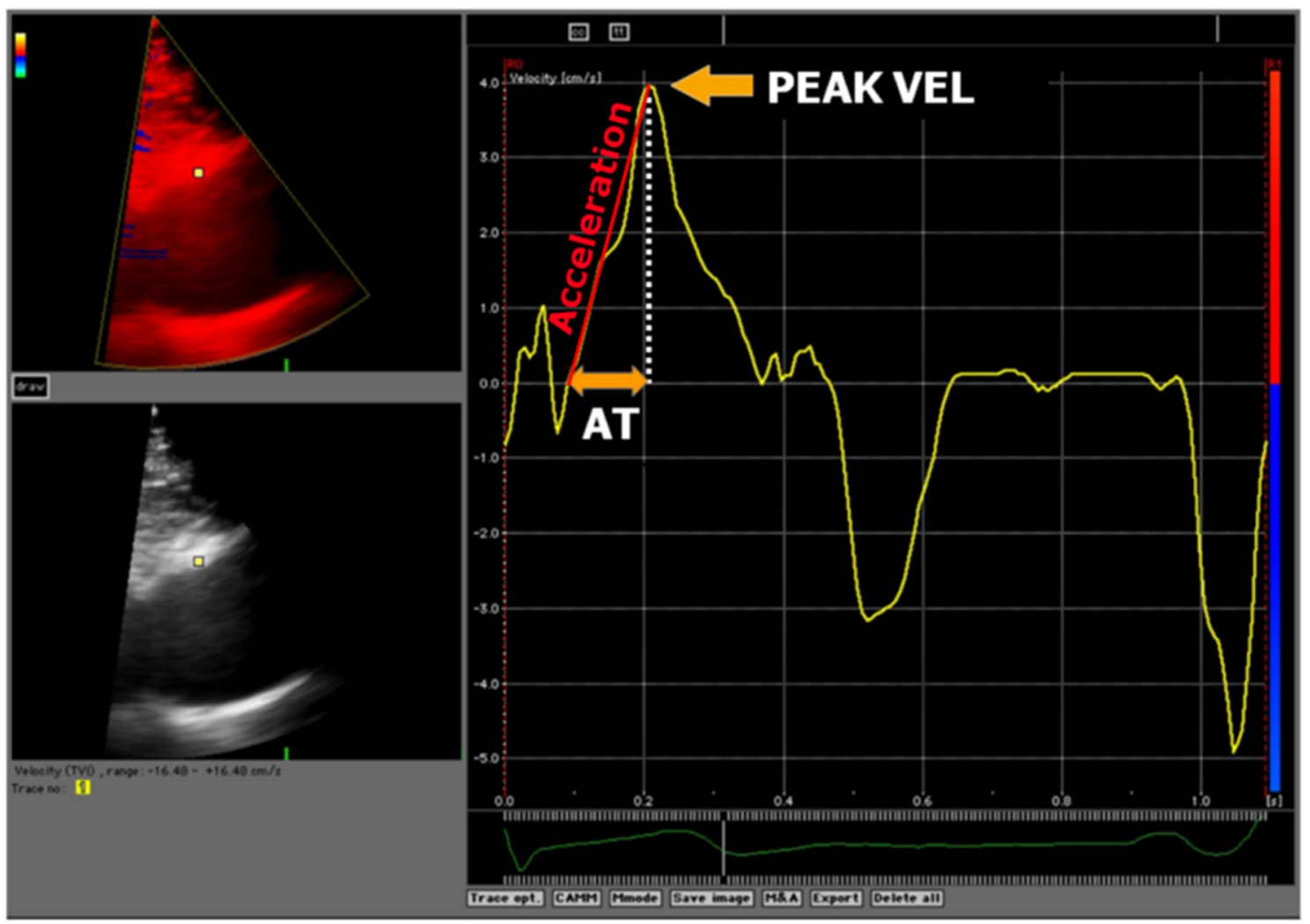

Fig. 1 Representative radial velocity curve of the anterior ascending aortic wall recorded by tissue Doppler imaging. Velocity curve was obtained from two-dimensional, color tissue Doppler image of the

analysis. Statistical calculations were performed with SAS software version 9.4 for Windows (SAS Institute Inc., Cary, NC, USA) and SAS macros for optimal matching created by the authors from Mayo Clinic (USA) [12]. Two-tailed P values $<0.05$ were considered statistically significant.

An informed consent was obtained from all the subjects. All study protocols were approved by the Institutional Review Board.

\section{Results}

An increased severity of the aortic stenosis, more dilated ascending aorta, but a lower peak systolic radial velocity and velocity acceleration of the anterior ascending aortic wall were observed in patients with right-noncoronary versus right-left coronary cusp fusion (Table 1). Patients with different cusps fusion were matched for clinical and echocardiographic parameters showing that velocity and acceleration of the aortic wall were still higher in patients with right-left coronary cusp fusion (Table 2).

Correlation analysis showed that ascending tubular aortic diameter was significantly and positively associated with ascending aorta in the parasternal long-axis view. The single arrow indicates peak systolic velocity of the anterior aortic wall. Oblique red Line represents acceleration. $A T$ acceleration time

age $(\mathrm{r}=0.258, \mathrm{p}=0.012)$, weight $(\mathrm{r}=0.323, \mathrm{p}=0.001), \log$ peak aortic valve gradient $(\mathrm{r}=0.386, \mathrm{p}=0.0001)$, aortic root diameter $(\mathrm{r}=0.439, \mathrm{p}<0.0001)$, and right-noncoronary fusion pattern $(r=0.209, p=0.043)$. Aortic root diameter was significantly and positively correlated with male gender $(r=0.296, p=0.003)$, weight $(r=0.381, p=0.0001)$, height $(\mathrm{r}=0.299, \mathrm{p}=0.003)$, ascending aortic diameter $(\mathrm{r}=0.439$, $\mathrm{p}<0.0001)$, and severity of aortic regurgitation $(r=0.337$, $\mathrm{p}=0.0009$ ).

\section{Discussion}

The results of our study suggest that local hemodynamic load imposed on the ascending aortic wall depends on the type of BAV fusion and severity of aortic valve disease and that TDI appears to be feasible for assessment of aortic hemodynamic. Aorta is the largest, most elastic artery. These properties allow for accommodation of extensive volume of pulsating blood flow with low resistance, thus diminishing left ventricular afterload. Aortic wall elasticity diminished progressively with increasing distance from the heart due to an increasing amount of collagen in relation to 
elastin fibers. This feature, along with elastic aortic recoil in diastole provides damping function (Windkessel effect) leading to protective nearly steady blood flow to end organs [13]. The mechanical function of the aorta is determined by its particular, three-layer structure. The main components responsible for aortic mechanical properties are situated primarily in tunica media, the thickest aortic layer. These are elastin fibers aligned in concentric elastic lamellae-the major determinants of aortic distensibility, collagen fibers providing tensile strength, as well as smooth muscle cells. A three-dimensional, highly organized structure is built by these constituents [14].

Elastic properties of aortic wall could be screened noninvasively by imaging techniques. This could be done by assessing changes in aortic volume in relation to pulse pressure (distensibility) or by measuring the time of blood flow wave traveling along the aorta (pulse wave velocity) [15]. While ultrasonography could be used here, advanced MRI is capable of simultaneously investigating these elastic parameters and hemodynamic behavior of the aorta [16].

There is a controversy regarding the pathogenesis of ascending aortic dilatation in BAV patients $[5,9]$. One theory suggests that developmental abnormalities of both aortic valve and the ascending aortic wall are present in BAV. The common embryological origin of these structures from the neural crest [17], the occurrence of aortic dilatation in first-degree relatives of BAV patients [18], presence of aortic dilatation out of proportion to the severity of aortic valve disease in early echocardiographic studies, [6, 7], as well as ongoing ascending aortic dilatation after aortic valve replacement [19] make this explanation probable [20]. Another theory is that disturbed aortic blood flow due to congenitally malformed BAV increases local hemodynamic forces which contribute to impairment of aortic media via mechanotransduction $[8,9]$.

The seminal study by Robicsek et al. on excised human aortic roots with BAV in the left heart simulator revealed structural malformations and reduced anatomic area despite apparently normal function of BAVs. These valve abnormalities were associated with formation of distinct large flow "vortices" that were not limited to the aortic sinuses, as in the case of tricuspid aortic valve, but they moved distally, increasing hemodynamic stress imposed primarily on the greater curvature of the ascending aorta [21].

Further advances in research of aortic hemodynamic were achieved by introducing three- and four- (time resolved)dimensional flow MRI [22]. In the recent flow-sensitive MRI studies, the pattern of aortic flow has been shown directly, which confirmed the above-mentioned observations. Extensive right-handed helical flow prevailed in BAV, with markedly asymmetric pattern of both postvalvular and distal flow, leading to increased aortic wall shear stress locally [23, 24].
Previous studies on BAV's have shown spatial differences concerning abnormalities of the ascending aortic media. Immuno-histochemistry of the aortic wall specimens in BAV patients revealed a decrease in smooth muscle cells and pathological changes in stress-related matrix protein composition which was observed especially in the areas where hemodynamic stress was expected to be higher (convexity of the ascending aorta) [25, 26].

A preliminary study using echocardiography for the assessment of ascending aortic hemodynamic was performed in patients with aortic stenosis, by determining the peak radial velocity of the aortic wall using TDI. An increased hemodynamic load imposed on the aortic wall was reported in bicuspid vs tricuspid valve patients. Furthermore, an asymmetric distribution of hemodynamic forces was recognized only in BAV patients, showing increased stress placed on the anterior aortic wall [10].

To the best of our knowledge, our study is the first to examine aortic hemodynamic in patients with different BAV cusp fusion pattern using TDI technique. One would expect that the higher blood flow induced by BAV would account for the increased systolic outward motion of the aortic wall. In our study, aortic blood flow has not been shown directly; instead, radial aortic wall motion was assessed which was assumed to be influenced by the hemodynamic burden caused by abnormal aortic flow. The influence of different patterns of BAV cusp fusion on aortic hemodynamic can be accurately determined only after adjustment for confounding factors that may affect aortic wall motion. Accordingly, we have matched right-noncoronary with right-left coronary cusp fusion patients not only for age and gender, but also for the aortic root and ascending aortic diameter, systolic blood pressure, and the severity of aortic stenosis and regurgitation.

The results of our study on BAV suggest that blood flow in the right-left coronary cusp fusion is directed through the aortic valve mainly towards the anterior wall of the ascending aorta, which is more susceptible to hemodynamic stress. This may result in the progressive damage to the aortic wall, and finally aortic dilatation (Fig. 2). Previous study demonstrated a greater aortic root diameter and the degree of morphological wall abnormalities in BAV patients with right-left coronary cusp fusion pattern [27].

In the recent BAV study histopathological changes in the aortic media were assessed together with the patterns of ascending aortic wall shear stress distribution showed by flow sensitive MRI. Degeneration of elastin and disturbances of matrix regulatory protein were found mainly in aortic areas of increased wall shear stress, suggesting a cause-andeffect relationship [28].

Recent MRI studies assessing aortic flow in BAV patients confirmed that in patients with right-left coronary cusp fusion a higher blood flow was directed towards 


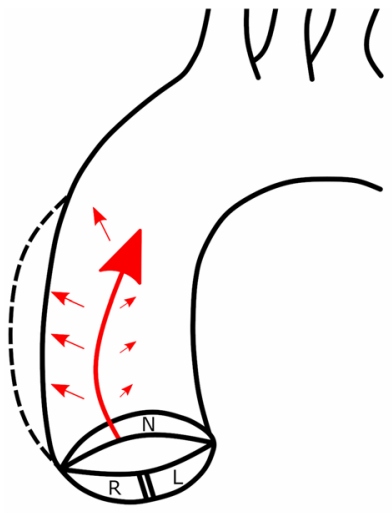

Right-left cusp fusion

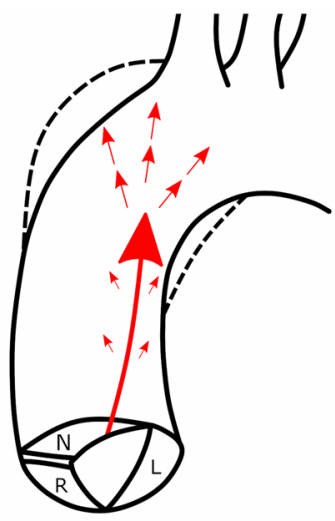

Right-noncoronary fusion

Fig. 2 Scheme of the of the bicuspid aortic valves with different type of cusp fusion. In right to left cusp fusion (see left) blood flow in aorta is directed more anteriorly and to the right impinging proximal ascending aortic wall (dilatation of mainly aortic sinuses), while in $\mathrm{R}-\mathrm{N}$ fusion (see right) blood travels posteriorly and to the left, thus increasing hemodynamic load on the aortic wall more distally (dilatation of mid-ascending aorta and even aortic arch). Such hemodynamic characteristics are directly observed by MRI and are also reflected by the results of our study

the antero-lateral wall of the ascending aorta contrary to right-noncoronary fusion where greater stress was found at posterior aortic wall [23, 29]. Similarly, our TDI study revealed increased systolic radial velocity and acceleration of the anterior aortic wall in BAV patients with right-left coronary cusp fusion contrary to right-noncoronary fusion. This suggests that screening for ascending aortic hemodynamic with this imaging technique seems feasible.

At present, ascending aortic diameter is used as almost sole but weak predictor of aortic dissection and rupture. BAV morphological phenotypes emerge as a new predictor of aortic remodeling. Aortic stenosis was observed to be associated with dilatation of ascending tubular aorta, while aortic regurgitation was correlated with dilatation of aortic sinuses [30]. Moreover R-N cusp fusion was associated with dilatation of predominantly ascending tubular aorta while R-L fusion was related to dilatation of aortic sinuses-root phenotype that was the most significant predictor of faster ascending aortic growth rate [31].

Research is ongoing to find new biomarkers predicting aortic complications in BAV predominantly among imaging techniques and blood parameters. Regarding imaging techniques there are initial attempts to translate advanced ultrasonography techniques used for heart studies to examine aortic wall biomechanics e.g. aortic wall strain with speckle tracking imaging introduced for screening ascending aortic stiffness [32] and subsequently used to study elastic aorta properties in BAV [33].

Emerging blood biomarkers of aortic wall damage in BAV are metalloproteinases (MMPs)—proteolytic enzymes capable of degrading extracellular matrix components of aortic media and tissue inhibitors of metalloproteinases (TIMPs),as well as transforming growth factor $\beta$ (TGF- $ß$ ) and specific microRNAs implicated in pathophysiology of aortic wall remodeling [34].

Genetic abnormalities may also belong here, e.g. mutations in NOTCH1, GATA family and ACTA2 genes which lead to BAV formation and could contribute to structural abnormalities of ascending aortic wall [35].

Aortic stenosis and regurgitation may increase the hemodynamic load imposed on the ascending aortic wall resulting in increased wall remodeling and aortic dilatation. In our study the relation between the severity of aortic valve disease and ascending aortic diameter was shown together with regional differences in aortic wall motion between different BAV cusp fusion patterns which seem to confirm hemodynamic impact of cusp fusion patterns and aortic valve dysfunction on ascending aortic wall. This is in agreement with previous echocardiographic studies in larger numbers of BAV patients showing a similar relation between aortic dilatation phenotype and degree of aortic stenosis and regurgitation [36, 37]. Recent MRI study in BAV patients revealed that the presence of moderate to severe aortic stenosis was associated with increased shear stress and aortic diameter as well as a more extensive helical and eccentric flow pattern in the ascending aorta [24].

\section{Limitations}

The relatively small number of women in our study makes it difficult to apply our results in this group.

Precise blood flow patterns in the aorta could not be directly visualized and elastic properties of the aortic wall were not studied in our exploratory echocardiographic study, but we believe that the relative influence of aortic stiffness on tissue Doppler indices of aortic wall motion should be studied by referred PWV method in gold-standard imaging technique i.e. advanced MRI. By using this imaging modality, elastic aortic properties, together with 3-dimensional disturbances of aortic flow could be described simultaneously. Nevertheless, taking into account costly and not widely available 4-D flow MRI software, using TDI parameters of aortic wall motion could improve the present limited prediction of ascending aortic complications in BAV patients.

\section{Conclusions}

Radial velocity and velocity acceleration of the ascending aortic wall, as assessed by TDI, were found to be associated with the cusps fusion pattern of BAV. This suggests that 
the hemodynamic stress placed on the ascending aortic wall depends on BAV phenotypes. A quantitative analysis of the ascending aortic wall motion using TDI is feasible and may be useful in the evaluation of aortic hemodynamic burden, as a new potential predictor of acute aortic complications. The severity of BAV stenosis and regurgitation was associated with ascending tubular aorta and aortic root dilatation, respectively, implying that these valve lesions induce hemodynamic impact on the aortic wall. At present, both increased hemodynamic burden induced by the diseased aortic valve and congenital abnormalities of the aortic wall are the most probable cause of progressive ascending aortic dilatation in BAV.

\section{Clinical perspectives}

Our findings suggest that TDI could be included in future BAV studies evaluating the importance of hemodynamic factors, both in the pathogenesis of the ascending aortic dilatation and in pharmacological or surgical treatment. This imaging modality may be useful for predicting aortic dilatation rate more precisely, which may help to better define the frequency of follow-up visits and the time of prophylactic surgical intervention on the aorta. Although our results should be confirmed by other studies, they appear to provide supporting evidence that hemodynamic stress plays an important role in the pathogenesis of BAV aortopathy. Tissue Doppler is a promising tool for the assessment of hemodynamic forces imposed on ascending aortic wall.

Acknowledgements All authors take a full responsibility for all aspects of the reliability and freedom from bias of the data presented and their discussed interpretation.

\section{Compliance with ethical standards}

Ethical approval This research did not receive any specific grant from funding agencies in the public, commercial, or not-for-profit sectors.

Conflict of interest All authors declare that they have no conflict of interest.

Open Access This article is licensed under a Creative Commons Attribution 4.0 International License, which permits use, sharing, adaptation, distribution and reproduction in any medium or format, as long as you give appropriate credit to the original author(s) and the source, provide a link to the Creative Commons licence, and indicate if changes were made. The images or other third party material in this article are included in the article's Creative Commons licence, unless indicated otherwise in a credit line to the material. If material is not included in the article's Creative Commons licence and your intended use is not permitted by statutory regulation or exceeds the permitted use, you will need to obtain permission directly from the copyright holder. To view a copy of this licence, visit http://creativecommons.org/licenses/by/4.0/.

\section{References}

1. Roberts WC (1970) The congenitally bicuspid aortic valve. A study of 85 autopsy cases. Am J Cardiol 26(1):72-83

2. Ward C (2000) Clinical significance of the bicuspid aortic valve. Heart 83(1):81-85

3. Michelena HI, Khanna AD, Mahoney D et al (2011) Incidence of aortic complications in patients with bicuspid aortic valves. JAMA 306(10):1104-1112

4. Huntington K, Hunter AG, Chan KL (1997) A prospective study to assess the frequency of familial clustering of congenital bicuspid aortic valve. J Am Coll Cardiol 30(7):1809-1812

5. Michelena HI, Della Corte A, Prakash SK et al (2015) Bicuspid aortic valve aortopathy in adults: Incidence, etiology, and clinical significance. Int J Cardiol 201:400-407

6. Hahn RT, Roman MJ, Mogtader AH et al (1992) Association of aortic dilation with regurgitant, stenotic and functionally normal bicuspid aortic valves. J Am Coll Cardiol 19(2):283-288

7. Nistri S, Sorbo MD, Marin M et al (1999) Aortic root dilatation in young men with normally functioning bicuspid aortic valves. Heart 82(1):19-22

8. Lehoux S, Castier Y, Tedgui A (2006) Molecular mechanisms of the vascular responses to hemodynamic forces. J Intern Med 259(4):381-392

9. Girdauskas E, Borger MA, Secknus MA et al (2011) Is aortopathy in bicuspid aortic valve disease a congenital defect or a result of abnormal hemodynamic? A critical reappraisal of a one-sided argument. Eur J Cardiothorac Surg 39(6):809-814

10. Bauer M, Siniawski H, Pasic M et al (2006) Different hemodynamic stress of the ascending aorta wall in patients with bicuspid and tricuspid aortic valve. J Card Surg 21(3):218-220

11. Baumgartner H, Hung J, Bermejo J et al (2017) Recommendations on the echocardiographic assessment of aortic valve stenosis: a focused update from the European Association of Cardiovascular Imaging and the American Society of Echocardiography European Heart. J Cardiovasc Imaging 18(3):254-275

12. Bergstralh EJ, Kosanke JL, Jacobsen SJ (1996) Software for optimal matching in observational studies. Epidemiology 7(3):331-332

13. Belz GG (1995) Elastic properties and Windkessel function of the human aorta. Cardiovasc Drugs Ther 9(1):73-83

14. Wagenseil JE, Mecham RP (2009) Vascular extracellular matrix and arterial mechanics. Physiol Rev 89(3):957-989

15. Oliver JJ, Webb DJ (2003) Noninvasive assessment of arterial stiffness and risk of atherosclerotic events. Arterioscler Thromb Vasc Biol 23(4):554-566

16. Whitlock MC, Hundley WG (2015) Noninvasive imaging of flow and vascular function in disease of the aorta. JACC Cardiovasc Imaging 8(9):1094-1106

17. Kappetein AP, Gittenberger-de Groot AC, Zwinderman AH et al (1991) The neural crest as a possible pathogenetic factor in coarctation of the aorta and bicuspid aortic valve. J Thorac Cardiovasc Surg 102(6):830-836

18. Loscalzo ML, Goh DL, Loeys B et al (2007) Familial thoracic aortic dilation and bicommissural aortic valve: a prospective analysis of natural history and inheritance. Am J Med Genet A 143A(17): 1960-1967

19. Yasuda H, Nakatani S, Stugaard M et al (2003) Failure to prevent progressive dilation of ascending aorta by aortic valve replacement in patients with bicuspid aortic valve: comparison with tricuspid aortic valve. Circulation 108(1):II291-II294

20. Cripe L, Andelfinger G, Martin LJ et al (2004) Bicuspid aortic valve is heritable. J Am Coll Cardiol 44(1):138-143 
21. Robicsek F, Thubrikar MJ, Cook JW et al (2004) The congenitally bicuspid aortic valve: how does it function? Why does it fail? Ann Thorac Surg 77(1):177-185

22. Kamphuis VP, Westenberg JJM, van der Palen RLF, Blom NA, de Roos A, van der Geest R, Elbaz MSM, Roest AAW (2017) Unravelling cardiovascular disease using four dimensional flow cardiovascular magnetic resonance. Int J Cardiovasc Imaging 33(7):1069-1081

23. Barker AJ, Markl M, Bürk J et al (2012) Bicuspid aortic valve is associated with altered wall shear stress in the ascending aorta. Circ Cardiovasc Imaging 5(4):457-466

24. Bissell MM, Hess AT, Biasiolli L et al (2013) Aortic dilation in bicuspid aortic valve disease: flow pattern is a major contributor and differs with valve fusion type. Circ Cardiovasc Imaging 6(4):499-507

25. Cotrufo M, Della Corte A, De Santo LS et al (2005) Different patterns of extracellular matrix protein expression in the convexity and the concavity of the dilated aorta with bicuspid aortic valve: preliminary results. J Thorac Cardiovasc Surg 130(2):504-511

26. Della Corte A, Quarto C, Bancone C et al (2008) Spatiotemporal patterns of smooth muscle cell changes in ascending aortic dilatation with bicuspid and tricuspid aortic valve stenosis: focus on cell-matrix signaling. J Thorac Cardiovasc Surg 135(1):8-18

27. Russo CF, Cannata A, Lanfranconi M et al (2008) Is aortic wall degeneration related to bicuspid aortic valve anatomy in patients with valvular disease? J Thorac Cardiovasc Surg 136(4):937-942

28. Guzzardi DG, Barker AJ, van Ooij P et al (2015) Valve-related hemodynamics mediate human bicuspid aortopathy: insights from wall shear stress mapping. J Am Coll Cardiol 66(8):892-900

29. Mahadevia R, Barker AJ, Schnell S et al (2014) Bicuspid aortic cusp fusion morphology alters aortic three-dimensional outflow patterns, wall shear stress, and expression of aortopathy. Circulation 129(6):673-682

30. Della Corte A, Bancone C, Quarto C, et al (2007) Predictors of ascending aortic dilatation with bicuspid aortic valve: a wide spectrum of disease expression. Eur J Cardiothorac Surg 31(3):397404; discussion 404-405
31. Della Corte A, Bancone C, Dialetto G, Covino FE, Manduca S, Montibello MV, De Feo M, Buonocore M, Nappi G (2014) The ascending aorta with bicuspid aortic valve: a phenotypic classification with potential prognostic significance. Eur J Cardiothorac Surg 46(2):240-247

32. Teixeira R, Monteiro R, Baptista R, Barbosa A, Leite L, Ribeiro M, Martins R, Cardim N, Gonçalves L (2015) Circumferential vascular strain rate to estimate vascular load in aortic stenosis: a speckle tracking echocardiography study. Int J Cardiovasc Imaging 31(4):681-689

33. Longobardo L, Carer ML, Pizzino G, Bitto A, Piccione MC, Zucco M, Oreto L, Todaro MC, Calabrò MP, Squadrito F, Di Bella G, Oreto G, Khandheria BK, Carerj S, Zito C (2018) Impairment of elastic properties of the aorta in bicuspid aortic valve: relationship between biomolecular and aortic strain patterns. Eur Heart J Cardiovasc Imaging 19(8):879-887

34. Naito S, Hillebrand M, Bernhardt AMJ, Jagodzinski A, Conradi L, Detter C, Sydow K, Reichenspurner H, Kodolitsch YV, Girdauskas E (2018) The value of circulating biomarkers in bicuspid aortic valve-associated aortopathy. Thorac Cardiovasc Surg 66(4):278-286

35. Giusti B, Sticchi E, De Cario R, Magi A, Nistri S, Pepe G (2017) Genetic bases of bicuspid aortic valve: the contribution of traditional and high-throughput sequencing approaches on research and diagnosis. Front Physiol 8:612

36. Davies RR, Kaple RK, Mandapati D et al (2007) Natural history of ascending aortic aneurysms in the setting of an unreplaced bicuspid aortic valve. Ann Thorac Surg 83(4):1338-1344

37. Kim YG, Sun BJ, Park GM et al (2012) Aortopathy and bicuspid aortic valve: haemodynamic burden is main contributor to aortic dilatation. Heart 98(24):1822-1827

Publisher's Note Springer Nature remains neutral with regard to jurisdictional claims in published maps and institutional affiliations. 